\title{
Evaluation of the Marker of Hypercoagulability Prothrombin Fragment $F$ 1+2 in Patients with Mechanical or Biological Heart Valve Prostheses
}

\author{
Claudia Natália Ferreira, Lauro Mello Vieira, Luci Maria Sant'Ana Dusse, \\ Carlos Faria Santos Amaral, William Antônio de Magalhães Esteves, \\ Lúcia Maria Amorim Fenelon, Maria das Graças Carvalho \\ Belo Horizonte, MG - Brazil
}

\begin{abstract}
Objective - To investigate whether patients with heart valve prostheses and similar International Normalized Ratios (INR) have the same level of protection against thromboembolic events, that is, whether the anticoagulation intensity is related to the intensity of hypercoagulability supression.
\end{abstract}

Methods - INR and plasma levels of prothrombin fragment $1+2(F 1+2)$ were assessed in blood samples of 27 patients ( 7 with mechanical heart valves and 20 with biological heart valves) and 27 blood samples from healthy donors that were not taking any medication.

Results - Increased levels of F1+2 were observed in blood samples of 5 patients with heart valve prostheses taking warfarin. These findings reinforce the idea that even though patients may have INRs, within the therapeutic spectrum, they are not free from new thromboembolic events.

Conclusion - Determination of the hypercoagulability marker $\mathrm{F} 1+2$ might result in greater efficacy and safety for the use of oral anticoagulants, resulting in improved quality of life for patients.

Keywords: heart valve prostheses, warfarin, prothrombin fragment $1+2$
Mailing address: Maria das Graças Carvalho - Depto de Análises Clínicas e Toxicológicas - Faculdade de Farmácia da UFMG - Av. Olegário Maciel, 2360 30180-112 - Belo Horizonte, MG - E-mail: pswanner@bhlink.com.br
Oral anticoagulants have been widely used to decrease the levels of vitamin K- dependent factors, that is II, VII, IX, and X, contributing to decreased thrombotic risk. Paradoxically, the use of anticoagulants reduces plasma levels of natural anticoagulants, $\mathrm{C}$ and $\mathrm{S}$ proteins, thus facilitating hypercoagulability. This fact raises concerns about the effects of oral anticoagulant use and its affects on hemostatic balance, protecting or not protecting the patient. Monitoring of oral anticoagulant therapy through measuring prothrombin time (PT) has contributed to substantial advances, revealed by the expression of the results of this test in terms of the International Normalized Ratio (INR), which contributes to the reduction of differences between results, therefore, making them more reliable. However, the use of prothrombin time as the method of choice for monitoring patients with heart valves who are taking oral anticoagulants is controversial. Are patients protected when the therapeutic range of IRN is similar to that expected? The number of patients with heart valve prostheses is significant, and they need anticoagulation medication for the rest of their lives, with constant monitoring. The main remaining problem is the thromboembolic potential of these valves ${ }^{1}$. Although the use of INR represents an advance in the interpretation of prothrombin time, some difficulties in monitoring anticoagulation therapy still occur, including limitations on the use of the INR system to asses the results of prothrombin time, floating on vitamin K intake, concomitant use of other drugs, difficulty in comprehension and/or acceptance of oral anticoagulants by the patients, concurrent diseases, and a genetic predisposition to thrombosis. In addition to factors already mentioned that contributed to the instability of oral anticoagulation, common to all patients receiving oral anticoagulants, factors are also inherent in patients with heart valve prostheses, which include the type, site, and number of replaced valves ${ }^{2}$. 
However, no consistent information is available on the extension of hemostatic mechanism activation in patients with a history of systemic thromboembolism without a definite defect in the coagulation system ${ }^{3}$. Thus, the benefits of the use of activation markers of coagulation, such as F1+2, have been emphasized for monitoring oral anticoagulant therapy ${ }^{4}$, because reduction in plasma levels of $F 1+2$ was demonstrated in patients with oral anticoagulant treatment. Thus, some investigators have presumed that warfarin dosage may be adjusted based on $\mathrm{F} 1+2$ concentrations ${ }^{5}$. Because prothrombin plays a fundamental role in the result of procoagulant stimulation, the quantification of $\mathrm{F} 1+2$ levels is considered one of the most important markers of hypercoagulability, reflecting the activation rate of prothrombin and, consequently, the levels of thrombin formed ${ }^{6}$. Elevation in F1+2 levels was observed in familial prethrombotic conditions, such as in antithrombin AT-III and C and S protein deficiencies.

The main purpose of this study was to investigate whether patients with similar INRs have the same protection against thromboembolic events, that is, whether the intensity of anticoagulation is related to the level of hypercoagulability supression. This study may contribute to a better understanding of the regulation of hemostatic mechanisms in therapy with oral anticoagulants and may also contribute to a better laboratory assessment of oral anticoagulant therapy in patients with heart valve prostheses, which would be clinically useful in the follow-up and prognosis of these patients.

\section{Methods}

We evaluated 54 patients: 27 patients were normal controls, 10 patients taking acetylsalicylic acid (Bio-AAS) had biological heart valve prostheses, 10 patients taking warfarin (Bio-War) had biological heart valve prostheses, and the remaining patients were taking warfarin (Mec-War) and had mechanical heart valve prostheses. Patients were consecutively enrolled at Hospitais das Clínicas, Vera Cruz, and Socor and were referred to the Laboratório de Hematologia Clínica da Faculdade de Farmácia da UFMG (Laboratory of Clinical Hematology of the College of Pharmacy of the Federal University of Minas Gerais). All the patients received stable doses of warfarin $(\mathrm{n}=17)$ and acetylsalicylic a$\operatorname{cid}(\mathrm{n}=10)$, for at least 1 month. The present study was approved by the Conselho Técnico Científico do Hospital das Clínicas da UFMG (Scientifical Technical Board of the Clinical Hospital of UFMG). Table I summarizes demographic characteristics and the number of patients from both study groups.

Venipunctures were performed in patients and in the control group after an 8-hour fast, and a 5-mL blood sample was drawn with vacuum tubes (Vacutainer system tube Becton-Dickinson) containing 3.8\% sodium citrate (anticoagulant: blood proportion 9:1), and processed as follows: blood samples were centrifuged at $2.500 \mathrm{rpm}$ for 10 minutes to obtain plasma poor in platelets. After centrifugation, plasma samples were aliquoted for different purposes: one was

\begin{tabular}{|lccccc|}
\hline \multicolumn{5}{|c|}{ Table I - Characterization of the groups of individuals studied } \\
\hline Groups & $\begin{array}{c}\text { Control } \\
\text { (n) }\end{array}$ & $\begin{array}{c}\text { Bio-AAS } \\
\text { (n) }\end{array}$ & $\begin{array}{c}\text { Bio-War } \\
\text { (n) }\end{array}$ & $\begin{array}{c}\text { Mec-War } \\
\text { (n) }\end{array}$ & $\begin{array}{c}\text { Total } \\
\text { (n) }\end{array}$ \\
\hline $\begin{array}{l}\text { Patients } \\
\text { Male sex }\end{array}$ & 27 & 10 & 10 & 7 & 54 \\
Female sex & 15 & 5 & 2 & 5 & 27 \\
Age average & 37 & 5 & 8 & 2 & 27 \\
(Age group) & $(17-64)$ & $(15-64)$ & 50 & 45 & - \\
\hline $\begin{array}{l}\text { Size of the sample (n), sex, age average, and age group of the groups studied: } \\
\text { normal control, patients with biological heart valve prostheses taking in } \\
\text { acetylsalicylic acid (Bio-AAS) or taking warfarin (Bio-War) and with } \\
\text { mechanical heart valve prostheses also taking warfarin (Mec-War). }\end{array}$ \\
\hline
\end{tabular}

separated for analysis of prothrombin time and INR up to 3 hours after collection. The other was frozen at $-20^{\circ} \mathrm{C}$ until the simultaneous testing of $\mathrm{F} 1+2$ from both patients and controls.

Prothrombin time and INR were determined with a coagulometer $\mathrm{ST}_{4}$-BIO (Diagnostica Stago, Asnieres-surSeine, France) that used rabbit brain thromboplastin (Biolab Merieux, São Paulo, Brasil, ISI=1.83). All plasma pools were diluted with saline solution $(0.85 \%)$ to determine the standard-curve. Plasma concentrations of F1+2 were determined with the enzyme immunoassay Enzygnost F1+2 micro (Behring Diagnostics GmbH, Marburg, Germany). This ELISA assay also uses microtitration plates, and readings were conducted on Bio- Rad (model 550).

\section{Results}

The results are presented in table II as mean \pm standard deviation. Differences between the groups were tested with analysis of variance followed by Tukey's test. A statistical significance level of $5 \%$ was adopted.

Regarding prothrombin time and INR, no significant difference was observed between the control group and the group of patients taking acetylsalicylic acid who had biological heart valves, whereas a significant statistical difference was observed between the control group and the group

\begin{tabular}{|c|c|c|c|c|}
\hline \multicolumn{5}{|c|}{$\begin{array}{c}\text { Table II - Results obtained in patients taking warfarin or acetyl- } \\
\text { salicylic acid and normal controls, regarding the } \\
\text { parameters studied }\end{array}$} \\
\hline Parameters & Control & Bio-AAS & Bio-War & Mec-War \\
\hline $\mathrm{AP}(\%)$ & $\begin{array}{c}84.2 \\
(11.4)\end{array}$ & $\begin{array}{l}83.0 \\
(10)\end{array}$ & $\begin{array}{c}48.9 \\
(15.5)\end{array}$ & $\begin{array}{l}38.6 \\
(8)\end{array}$ \\
\hline INR & $\begin{array}{c}1.15 \\
(0.16)\end{array}$ & $\begin{array}{c}1.19 \\
(0.13)\end{array}$ & $\begin{array}{c}2.33 \\
(0.93)\end{array}$ & $\begin{array}{c}2.83 \\
(1.1)\end{array}$ \\
\hline $\mathrm{F} 1+2(\mu \mathrm{mol} / \mathrm{L})$ & $\begin{array}{c}0.62 \\
(0.22)\end{array}$ & $\begin{array}{c}0.72 \\
(0.36)\end{array}$ & $\begin{array}{c}0.64 \\
(0.41)\end{array}$ & $\begin{array}{c}0.63 \\
(0.48)\end{array}$ \\
\hline \multicolumn{5}{|c|}{$\begin{array}{l}\text { Mean and standard deviation of the results obtained from normal control, } \\
\text { patients with biological heart valve prostheses taking acetylsalicylic acid } \\
\text { (Bio-AAS) or warfarin (Bio-War) and with mechanical heart valve pros- } \\
\text { theses taking warfarin (Mec-War) regarding the parameters studied. PT- } \\
\text { prothrombin time; INR- International Normalized Ratio; F1+2 prothrombin } \\
\text { fragment } 1+2 \text {. }\end{array}$} \\
\hline
\end{tabular}


of patients taking warfarin who had biological and mechanical heart valves $(\mathrm{P}<0.05)$.

Analysis of the results showed that the marker of prothrombin activation, fragment $\mathrm{F} 1+2$, was not significantly different between the groups studied, although great variation inside the groups occurred. The highest $\mathrm{F} 1+2$ result was observed in a patient with mechanical heart valves taking 2 warfarin pills a day, which was the maximun anticoagulant dose used in this study. The results of $\mathrm{F} 1+2$ determination in patients with heart valve prostheses in general are shown in table III. Of 27 patients with heart valves taking warfarin or acetylsalicylic acid, 5 had F1+2 levels above the reference range. No correlation between the results of $\mathrm{F} 1+2$ and INR were observed when all patients were compared as a whole. However, because the patients with mechanical heart valves constitute a group with greater thromboembolic risk and therefore, are mandatory users of oral anticoagulation, we also investigated the correlation between INR values and $\mathrm{F} 1+2$ for this group, aiming at determining whether the level of anticoagulation was related to supression of the hypercoagulability state. No correlation was observed between INR values and F1+2, for the mechanical heart valve group, although this group used higher doses of oral anticoagulants and, thus, had mean INR values higher than those of the other groups. Results of individual values for INR and F1+2 in the mechanical heart valve prostheses group are presented in table IV.

Regarding the dosage of warfarin used by patients, significant differences were not observed between levels of PT, INR, and F1+2 when dosages lower than, equal to, or greater than $35 \mathrm{mg} /$ week were compared (tab. V).

The group of patients taking oral anticoagulants who had mechanical heart valves are divided into low-intensity warfarin $(\mathrm{INR}=1.2-1.4)$; moderate-intensity warfarin $(\mathrm{INR}=$ 1.5-3.0), and high-intensity warfarin (INR $>3.0$ ) groups and are presented in table VI. In the present study, of the 7 patients with mechanical heart valves, 6 had INR values between 1.5 and 3.0.

\section{Discussion}

Through data analysis, we observed that acetylsalicylic acid did not change the results of prothrombin time or INR in patients with biological heart valves.

\begin{tabular}{|c|c|c|c|c|}
\hline \multicolumn{5}{|c|}{$\begin{array}{l}\text { Table III - Number of patients with heart valve prostheses with F1+2 } \\
\text { results lower, within, or below reference values } \\
(0.4 \text { to } 1.1 \mu \mathrm{mol} / \mathrm{L})\end{array}$} \\
\hline $\mathrm{F} 1+2$ values & Bio-AAS & Bio-War & Mec-War & Total \\
\hline Lower than $0.4 \mu \mathrm{mol} / \mathrm{L}$ & 2 & 3 & 3 & 8 \\
\hline From 0.4 a $1.1 \mu \mathrm{mol} / \mathrm{L}$ & 6 & 5 & 3 & 14 \\
\hline Above $1.1 \mu \mathrm{mol} / \mathrm{L}$ & 2 & 2 & 1 & 5 \\
\hline \multicolumn{5}{|c|}{$\begin{array}{l}\text { Bio-AAS - patients taking acetylsalicylic acid with biological heart valve } \\
\text { prostheses; Bio-War - patients with biological heart valve prostheses } \\
\text { taking warfarin; Mec-War - patients with mechanical heart valve pros- } \\
\text { theses taking warfarin. }\end{array}$} \\
\hline
\end{tabular}

\begin{tabular}{|lcc|}
\hline \multicolumn{3}{|c|}{$\begin{array}{c}\text { Table IV - Results of individual values for INR and F1+2 in the group } \\
\text { of patients with mechanical heart valve prostheses } \\
\text { taking warfarin }\end{array}$} \\
\hline Patients & INR & $\mathrm{F} 1+2$ \\
\hline \multirow{2}{*}{$\begin{array}{l}\text { (NR } \\
2\end{array}$} & 2.46 & 0.64 \\
3 & 2.53 & 0.30 \\
4 & 2.07 & 1.06 \\
5 & 5.30 & 1.50 \\
6 & 2.60 & 0.48 \\
7 & 2.50 & 0.24 \\
& 2.83 & 0.20 \\
\hline \multirow{2}{*}{ INR- international normalized ratio; F1+2 - 1+2 prothrombin fragment. } \\
\hline
\end{tabular}

\begin{tabular}{|c|c|c|c|}
\hline \multicolumn{4}{|c|}{ Table $V$ - Effects of warfarin dosage on the parameters studied } \\
\hline Parameters & $\begin{array}{c}\text { Lower than } \\
35 \mathrm{mg} / \mathrm{sem}(\mathrm{n}=6)\end{array}$ & $\begin{array}{c}\text { Equal to } \\
35 \mathrm{mg} / \mathrm{sem}(\mathrm{n}=7)\end{array}$ & $\begin{array}{l}\text { Higher than } \\
35 \mathrm{mg} / \mathrm{sem}(\mathrm{n}=4)\end{array}$ \\
\hline PT (\%) & 48.6 & 43.5 & 40.7 \\
\hline INR & 2.3 & 2.5 & 3.1 \\
\hline $\mathrm{F} 1+2(\mu \mathrm{mol} / \mathrm{L})$ & 0.60 & 0.69 & 0.60 \\
\hline \multicolumn{4}{|c|}{$\begin{array}{l}\text { Mean of studied parameters: PT- prothrombin time; INR- international nor- } \\
\text { malized ratio; F1+2 }-1+2 \text { prothrombin fragment in patients with mechanical } \\
\text { or biological heart valve prostheses taking warfarin, at doses lower than, } \\
\text { equal to, or higher than } 35 \mathrm{mg} / \text { week. No significant difference existed when } \\
\text { the effect of different warfarin dosages was compared with to the parameters } \\
\text { studied. }\end{array}$} \\
\hline
\end{tabular}

Patients with biological heart valves generally experience fewer thromboembolic events, compared with those with mechanical heart valves and, therefore, most of these patients use only acetylsalicylic acid. In the present study, we observed patients with plasma F1+2 levels above reference levels (tab. III). However, it is possible that other factors may be interacting in these patients, resulting in an apparent state of hypercoagulability suggested by the increased levels of $\mathrm{F} 1+2$.

Despite a suitable monitoring through prothrombin time, approximately 10 to $20 \%$ of the patients treated with warfarin developed thromboembolic or bleeding complications because of inadequate warfarin therapy. Although some of these complications may occur when prothrombin time is out of therapeutical range, about $50 \%$ of the complications occur when prothrombin time is within this range ${ }^{7}$, strengthening the idea that the introduction of a marker hypercoagulability,

\begin{tabular}{|c|c|}
\hline \multicolumn{2}{|c|}{$\begin{array}{l}\text { Table VI - Number of patients with mechanical heart valve prostheses } \\
\text { divided into: low- intensity warfarin, moderate-intensity warfarin, } \\
\text { and high-intensity warfarin }{ }^{10}\end{array}$} \\
\hline Level of anticoagulation & Number of patients \\
\hline Low intensity $(\mathrm{INR}=1.2-1.4)$ & 0 \\
\hline Moderate intensity $(\mathrm{INR}=1.5-3.0)$ & 6 \\
\hline High intensity $($ INR $>3.0)$ & 1 \\
\hline
\end{tabular}


together with INR, may bevery useful for improving monitoring of patients receiving oral anticoagulants.

The benefits of determining markers of activated coagulation in monitoring oral anticoagulant therapy have been studied mainly by Conway et al. ${ }^{8}$, the first to demonstrate $F 1+2$ supression in patients stabilized with an oral anticoagulant. Because of that, studies have been carried out to analyze the adjustment of warfarin dosage, using as a base $\mathrm{F} 1+2$ concentration ${ }^{5}$. F $1+2$ concentration in patients stabilized with oral anticoagulants was determined in the present study, and no correlation was observed between F1+2 concentration and the level of anticoagulation expressed as an INR. Despite the absence of a correlation between these 2 parameters, we cannot establish a parallel between the level of supression of hypercoagulability through the results of the marker of thrombin $\mathrm{F} 1+2$ generator, and the intensity of anticoagulation through INR values. Table II shows that no significant difference exists regarding $\mathrm{F} 1+2$ levels, between the groups using warfarin and the control groups. However, isolated cases with increased F1+2 levels were found in our study, which enabled us to make inferences about the potential for the occurrence of a new thrombotic event.

Barcellona et $\mathrm{al}^{9}$ and Tripodi et $\mathrm{al}^{4}$ demonstrated that $\mathrm{F} 1+2$ is a sensitive marker of anticoagulation, even when the intensity of treatment is very low. A statistically significant progressive decrease occurred in F1+2 levels with increasing anticoagulation up until an INR value of 3.0. The F1+2 decrease, however, was barely detectable at INR values $>3.0$. The reason for this pattern is not clear.

Jafri et al ${ }^{10}$ worked with 3 groups of patients with heart failure, and the groups were treated with placebo, low-intensity warfarin $(\mathrm{INR}=1.2-1.4)$, and moderate-intensity warfarin $(\mathrm{INR}=1.5-3.0)$. They observed that the markers of hypercoagulability TAT (thrombin-anti-thrombin complexes), D-dimers, and F1+2 decreased with the increase in oral anticoagulant intensity. However, patients with increased F1+2 levels were observed in the groups treated with placebo and in the groups treated with warfarin after 3 months of treatment.

The majority of patients had an adequate intensity of anticoagulation, as we can see in table VI. Table IV summarizes INR and F1+2 levels from patients with mechanical heart valves. Considering the results presented in these tables, it can be suggested that F1+2 determination is an important tool in selecting patients at risk of developing thrombotic events, considering that the great majority of patients seemed stably anticoagulated, considering INR values as parameters. Data analysis of each patient shows that activation of the coagulation mechanism may occur, which can be verified by increased F $1+2$ levels, is spite of adequate values for INR. This stresses the potentiality of the use of F1+2, an important marker of thrombin generation, therefore, a marker of hypercoagulability, in such patients, since they have greater thromboembolic risk for eventual coagulation hyperactivation.

In the present study, 5 patients had $\mathrm{F} 1+2$ values abo- ve the reference range, while 14 patients were within this range and 8 patients were below it (tab. III). F1+2 increase observed in 5 patients may be explained because of heterogenity in warfarin bioavailibility, prostheses characteristics, and because of concomitant diseases ${ }^{11}$. However, the relevance of $\mathrm{F} 1+2$ values observed in this study needs to be confirmed in a longer follow-up, seeking the establishment of the relationship between increased $\mathrm{F} 1+2$ levels and recurrence of thromboembolic events.

We must consider that our patients were undergoing oral anticoagulation therapy throughout the period of the study, and they were at potential risk of hypercoagulability resulting mainly from mechanical heart valve prostheses or, to a lesser degree in, from biological heart valve prostheses.

INR values of 2.0-3.0, corresponding to prothrombin levels of approximately $20-40 \%$ of the normal have been considered acceptable ${ }^{12}$. However, the minimal level of each Vitamin K-dependent protein required to protect the patient from thrombosis has still not been determined. Thus, F1+2 measurement may be useful as a tool in monitoring patients receiving oral anticoagulants.

Our data questions the protective effect of warfarin against thromboembolic events once F1+2 levels are increased in some patients taking oral anticoagulants with heart valve prostheses. According to the literature, levels of hypercoagulability markers are reduced in patients receiving oral anticoagulants ${ }^{8,10}$. However, the use of these markers as a tool to preview thromboembolic complications has still not been well analyzed in patients with heart valve prostheses receiving oral anticoagulants or acetylsalicylic acid. Additionally, data in the literature suggest that the intensity of oral anticoagulants is associated with the level of hypercoagulability supression. However, evidence exists of increased fibrinolitic activity as well as platelet activation, and abnormal endothelial function in patients with heart failure ${ }^{12,13}$. It is possible that the hypercoagulability state predisposes heart failure patients to intravascular thrombi and an increase in clinical events ${ }^{10}$. The oral anticoagulant dosage necessary to minimize this state of hypercoagulability varies from patient to patient. Thus, reduced dosages may be efficient for some patients, but other patients may need an increased dosage of oral anticoagulants or even the combination of an oral anticoagulant and acetylsalicylic acid ${ }^{14}$.

Comparing our data with that in the literature, $\mathrm{F} 1+2$ levels observed in some patients in our study were more elevated than expected taking into account that these patients were taking an oral anticoagulant. This fact stresses the importance of $\mathrm{F} 1+2$ use to identify patients at risk of developing thromboembolic events, even when the patient has an INR within the therapeutic range. These patients should be followed-up with greater care to find the possible causes that could justify the presence of a hypercoagulability condition. As already mentioned, several triggering factors of this condition may be interacting parallel to the thrombogenic effect of the prostheses in itself. A critical assessment of the risks of patients could result in adequate 
treatment of concomitant diseases. In the absence and/or impossibility of its diagnosis, the possibility of adding an antiagregating platelet agent to oral anticoagulant therapy must be considered. This procedure instead of increasing the need for oral anticoagulant dosing would possibly result in a reduction in the risk of thromboembolic complications (which could be verified by a new assessment of F1+2 levels) and would not increase hemorrhagic risk. This measure, probably, would result in greater efficacy and safety for the use of oral anticoagulants, providing a better quality of life for patients. However, further studies involving new experiments and others markers of coagulability in addition to F1+2 are necessary, using a larger sample of patients with heart valve prostheses to confirm whether the reduction in thromboembolic events is related to lower events of F1+2 during concomitant use of oral anticoagulants and acetylsalicylic acid.

\section{Acknowledgments}

To Fundação de Amparo à Pesquisa de Minas Gerais (FAPEMIG) (Foundation to Support Research), to CNPq, and Pró-Reitoria de Pesquisa (PRPq) of Universidade Federal de Minas Gerais by the finantial support.

\section{References}

1. Cannegieter SC, Rosendaal FR, BriëtE. Thromboembolic and bleeding complications in patients with mechanical heart valve prostheses. Circulation 1994; 89: 635-41.

2. Saour JN, Sieck JO, Mamo LAR, Gallus AS. Trial of different intensities of anticoagulation in patients with prosthetic heart valves. N Engl J Med 1990; 322: 428-32.

3. Kyrle PA, Eichinger S, Pabinger I, et al. Prothrombin fragment F1+2 is not predictive for recurrent venous thromboembolism. Thromb Haemost 1997; 77: 829-33.

4. Tripodi A, Cattaneo M, Molteni A, Cesana BM, Mannucci PM. Changes of prothrombin fragment $1+2(F 1+2)$ as a function of increasing intensity of oral anticoagulation. Thromb Haemost 1998; 79: 571-3.

5. Tripodi A, Mannucci PM. Markers of activated coagulation and their usefulness in the clinical laboratory. Clin Chem 1996; 42: 664-9.

6. Rugman FP, Jenkins JA, Duguid JK, Maggs PB, Hay CRM. Prothrombin fragment F1+2: correlations with cardiovascular risk factors. Blood Coag Fibrinol 1994; 5: 335-40

7. Furie B, Diuguid CF, Jacobs M, Diuguid DL, Furie BC. Randomized prospective trial comparing the native prothrombin antigen with the prothrombin time for monitoring oral anticoagulant therapy. Blood 1990; 75: 344-9.
8. Conway EM, Bauer KA, Barzegar S, Rosenberg RD. Suppression of hemostatic system activation by oral anticoagulants in the blood of patients with thrombotic diatheses. J Clin Invest 1987; 80: 1535-44.

9. Barcellona D, Mameli G, Marongiu F. Inhibition of blood coagulation activation and oral anticoagulants in patients with mechanical heart valve prostheses. Thromb Res 1996; 81: 403-6.

10. Jafri SM, Mammen EF, Masura J, Goldstein S. Effects of warfarin on markers of hypercoagulability in patients with heart failure. Am Heart J 1997; 134: 27-36.

11. Koefoed BG, Feddersen C, Gullov AL, Peterson P. Effect of fixed minidose warfarin, conventional dose warfarin and aspirin on INR and prothrombin fragment $1+2$ in patients with atrial fibrillation. Thromb Haemost 1997; 77: 845-8.

12. Jafri SM, Ozawa T, Mammen E, Levine TB, Johnson C, Goldstein S. Platelet function, thrombin and fibrinolytic activity in patients with heart failure. Eur Heart J 1993; 14: 205-12.

13. SborouniE, Bradshaw H, Andreath F, Tuddenham E, Dakley CM, Cleland JGF. Relationship between hemostatic abnormalities and neuroendocrine activity in heart failure. Am Heart J 1994; 127: 607-12.

14. Bruhn HD, Seisch J, Wagner C. Documentation of hypercoagulability by measurement of prothrombin fragment $\mathrm{F} 1+2$ when introducing oral anticoagulant therapy. Thromb Res 1992; 68:317-9. 